Conclusions Bedside chest ultrasound prior to pleural procedures in this cohort resulted in a change in the preferred site in a considerable number of patients. Ultrasound increased the level of confidence with the selected pleural procedures and resulted in a change to the intended procedure in $23 \%(11 / 47)$ of cases which included completely abandoning the procedure in $12.7 \%$ of cases $(6 / 47)$.

\section{P31 ROUTINE ANALYSIS OF PLEURAL ASPIRATES FOR AFB IN PATIENTS WITH PLEURAL EFFUSION OF UNKNOWN CAUSE IS OF LIMITED USE}

doi:10.1136/thoraxjnl-2011-201054c.31

P K Agarwal, M Ali, J Keane, S Barrett, S 0 Ansari. Southend University Hospital, Southend, UK

The investigation of pleural effusion of unknown cause may include analysis of pleural aspirate for presence of acid-fast bacilli (AFB) by smear and culture. We reviewed data on all pleural aspirates sent for AFB analysis over 11 years (January 2000 to December 2010) to identify the diagnostic yield of pleural aspirate AFB smear and culture in our hospital where there is a low incidence of tuberculosis (TB). Data were crosschecked with the TB notification list obtained from the Consultant in Communicable Disease Control (CCDC) to ensure identification of all tuberculous effusions. A list of all AFB positive specimens (including smears, cultures and histology) was also obtained from the pathology laboratory. The medical records of patients with AFB positive aspirates were reviewed. We also reviewed the medical records of patients with AFB negative pleural effusion who were diagnosed to have TB by other means. In total, 960 pleural aspirate samples were sent for AFB analysis. None of these were smear positive and only $13(1.4 \%)$ were found to be positive on cultures. The ethnic breakdown of this figure was one, five, and seven cases for Asian, Caucasian, and Afro-Caribbean patients, respectively. Five of these patients were known or found to be HIV positive, all of whom were Afro-Caribbean. Eight of the 13 patients with positive pleural aspirate cultures underwent pleural biopsy (three by thoracoscopy), all of which confirmed a diagnosis of TB. One patient with positive cultures of pleural aspirate also had TB confirmed on culture of bronchial washings. A further ten patients $(1 \%)$ whose pleural aspirates were AFB negative on smear and culture were diagnosed with tuberculosis by other means. The yield of AFB analysis on pleural aspirate is very low. Its role in commencing treatment in those who ultimately are diagnosed to have tuberculosis is limited. Risk factors for tuberculosis need to be considered before sending aspirate for AFB analysis. Where risk of TB is considered to be significant, pleural fluid aspiration should be combined with simultaneous pleural biopsy, as the latter may provide crucial diagnostic information at an earlier stage.

\section{P32 ARE JUNIOR DOCTORS SAFE TO PERFORM PLEURAL PROCEDURES? AN AUDIT OF JUNIOR DOCTOR KNOWLEDGE AND COMPETENCY OF PLEURAL PROCEDURES BEFORE AND AFTER DEDICATED LECTURE-BASED AND PRACTICAL TEACHING SESSIONS}

doi:10.1136/thoraxjn-2011-201054c.32

S V Ruickbie, G MacDonald, N Walters, A Draper, Y E Ong. St Georges Hospital, London, UK

Introduction Pleural procedures are considered core competencies at the end of ST2 medical training but with the advent of subspecialisation within medicine and reduced working hours, junior doctors may have less exposure to these procedures.
Aims and Objectives One of the major themes that arose from the 2008 Rapid Response Report was inexperienced doctors undertaking procedures. We sought to determine the level of knowledge and competency at pleural procedures of junior doctors (F1-ST2) before and after teaching sessions to assess whether improvement occurred.

Methods Junior doctors were asked to complete a questionnaire in early 2011 about their self-assessed level of competency at pleural procedures and testing knowledge on various aspects of chest drain insertion and removal. A series of lectures at "mandatory" teaching days and optional practical drain insertion sessions on animal cadavers were delivered and junior doctors were asked to repeat the questionnaire between June and July 2011.

Results 57 doctors filled in the questionnaire pre-teaching and 37 completed in after teaching. Please see Abstract P32 table 1 for results. On re-audit, some of the most concerning findings were that 1 out of the 5 ST2 trainees had performed $<3$ thoracocentesis and 3 out of the 5 had performed $<3$ Seldinger chest drain insertion ( 1 never performed procedure) just prior to the completion of their ST2 rotation.

Abstract P32 Table 1 Table showing results of pleural audit before and after teaching

\begin{tabular}{|c|c|c|}
\hline & Pre-teaching & Post-teaching \\
\hline Number completing survey & $\begin{array}{l}57 \text { doctors }(53 \% \\
\text { foundation, } \\
47 \% \text { ST1/2) }\end{array}$ & $\begin{array}{l}37 \text { doctors }(35 \% \\
\text { foundation, } 36 \% \\
\text { ST1/2, } 27 \% \text { unknown) }\end{array}$ \\
\hline Number (and \%) & 22 (39\% of total) & $16(43 \%$ of total $)$ \\
\hline $\begin{array}{l}\text { self-judged to be } \\
\text { competent at } \\
\text { thoracocentesis }\end{array}$ & $\begin{array}{l}\text { Of these } 14 \\
\text { ( } 25 \% \text { of total) } \\
\text { performed } \\
\text { procedure }>3 \text { times }\end{array}$ & $\begin{array}{l}\text { Of these } 13(35 \% \text { of } \\
\text { total) performed } \\
\text { procedure }>3 \text { times }\end{array}$ \\
\hline Number (and \%) & $15(26 \%$ of total) & $12(32 \%$ of total) \\
\hline $\begin{array}{l}\text { self-judged to be } \\
\text { competent at Seldinger } \\
\text { drain insertion }\end{array}$ & $\begin{array}{l}\text { Of these } 5 \text { ( } 9 \% \text { of total) } \\
\text { performed procedure } \\
>3 \text { times }\end{array}$ & $\begin{array}{l}\text { Of these } 8(22 \% \text { of } \\
\text { total) performed } \\
\text { procedure }>3 \text { times }\end{array}$ \\
\hline Number (and \%) & $5(9 \%$ of total) & $6(16 \%$ of total $)$ \\
\hline $\begin{array}{l}\text { self-judged to be } \\
\text { competent at large } \\
\text { bore drain insertion }\end{array}$ & $\begin{array}{l}\text { Of these } 1 \\
\text { ( } 2 \% \text { of total) } \\
\text { performed } \\
\text { procedure }>3 \text { times }\end{array}$ & $\begin{array}{l}\text { Of these } 3 \text { ( } 8 \% \text { of total } \\
\text { performed procedure } \\
>3 \text { times }\end{array}$ \\
\hline Percentage who & $56 \%$ & $73 \%$ \\
\hline
\end{tabular}

would obtain

written consent

for plural procedures

Percentage correctly

identifying triangle

of safety

Percentage correctly

identifying area for

emergency

decompression of

tension pneumothorax

Percentage choosing

large bore venflon for

tension pneumothorax

decompression

Percentage who would

remove a bubbling

chest drain

$31 \%$ (grey and orange) $\quad 32 \%$ (grey and orange)

Conclusion Dedicated teaching covering all aspects tested in the questionnaire led to an improvement in theoretical knowledge about pleural procedures but worrying basic deficiencies remain. It is uncertain whether the trainees had not attended teaching or had not absorbed the information. In addition junior doctors still perform relatively few pleural procedures. Of particular concern, some ST2s who are shortly to be medical SpRs have performed very few pleural procedures which are part of their core competency. Whether this is 
due to lack of opportunity due to reduction in hours or other factors is uncertain. This may represent a significant risk for patients presenting out of hours who require an emergency pleural procedure.

\section{P34 ARE NURSING STAFF SUFFICIENTLY EDUCATED AND COMPETENT IN MANAGING PATIENTS WITH A CHEST DRAIN?}

doi:10.1136/thoraxjnl-2011-201054c.34

G Fremlin, R Baker, G Walters, T Fletcher. Good Hope Hospital, Heart of England Foundation Trust, Birmingham, UK

Background The British Thoracic Society recommends that patients with chest drains should be nursed on a ward familiar with their care. Instruction from doctors and appropriate training of nursing staff is imperative to minimise complications associated with chest drains. Our audit aimed to determine the nurses' level of knowledge regarding chest drain management and the support and direction provided by doctors following drain insertion.

Methods We undertook a prospective case-note audit of chest drain insertion, management and complication rates. In addition we interviewed 100 nurses across medical wards familiar with chest drains, and they undertook a structured questionnaire about training, knowledge and confidence in chest drain care.

Results 29 chest drains were inserted. $65 \%$ patients suffered no complications but $25 \%$ patients reported pain during or following drain insertion. Potential for serious incidents was high; $20 \%$ of effusions drained $>21$ within the first hour and $10 \%$ of pneumothoraces were clamped following insertion. Although all nurses reported to have managed a drain only $12 \%$ had received formal training and only $34 \%$ felt confident in managing a drain. Complication rates correlated with nurses' responses; 34\% believed painrelief was only indicated following insertion; $8 \%$ would clamp a drain inserted for a pneumothorax, while $20 \%$ were unsure whether a pneumothorax drain should be clamped; $16 \%$ believed pleural effusion drains should never be clamped, while $28 \%$ were unsure. Of those who believed an effusion drain should be clamped, 29\% felt this was indicated after $>21$ was drained within the first hour. Of concern, nurses on respiratory wards appeared to have limited knowledge of drain management. $78 \%$ of nurses felt poor instruction was provided by ward doctors with regard to chest drain management.

Conclusions Lack of evidence-based nursing care and insufficient training has resulted in uncertainty and knowledge deficit in important aspects of chest drain care, exposing patients to avoidable complications. Poor instructions to nurses from doctors following drain insertion further compromises patient care. A carefully designed and implemented care bundle to guide nurses through drain management could significantly lower post-insertion complications; an example has been rolled out and is illustrated.

Conclusions The majority of specialty trainees have access ultrasound on the ward and have attended a thoracic ultrasound training course. However, it is concerning that very few trainees have a regular dedicated ultrasound training session or a training mentor. If all trainees are to achieve level one competency by the completion of specialty training, there needs to be more importance placed on practical training and the maintenance of a log book.

\section{Abstract P33 Table 1}

\begin{tabular}{|c|c|c|c|c|c|}
\hline & \multicolumn{2}{|c|}{ District General $(n=69)$} & \multicolumn{2}{|c|}{ Teaching Hospital $(n=83)$} & \\
\hline & Yes & No & Yes & No & \\
\hline $\begin{array}{l}\text { Access to ultrasound } \\
\text { on the ward }\end{array}$ & $59(73 \%)$ & $22(27 \%)$ & $67(75 \%)$ & $22(25 \%)$ & $\begin{array}{l}\chi^{2}=0.13 \\
p=0.72\end{array}$ \\
\hline $\begin{array}{l}\text { Regular dedicated } \\
\text { ultrasound training } \\
\text { session }\end{array}$ & $8(10 \%)$ & $73(90 \%)$ & $19(21 \%)$ & $70(79 \%)$ & $\begin{array}{l}\chi^{2}=4.18 \\
\mathbf{p}=0.04\end{array}$ \\
\hline $\begin{array}{l}\text { Ultrasound training } \\
\text { mentor }\end{array}$ & $27(33 \%)$ & $54(67 \%)$ & $39(46 \%)$ & $50(56 \%)$ & $\begin{array}{l}\chi^{2}=1.96 \\
p=0.16\end{array}$ \\
\hline
\end{tabular}

\section{P35 PRIMARY SPONTANEOUS PNEUMOTHORAX: ADHERENCE TO GUIDELINES AND HEALTHCARE ECONOMIC IMPLICATIONS}

doi:10.1136/thoraxjnl-2011-201054c.35

${ }^{1} \mathrm{G}$ D Thomas, ${ }^{2} \mathrm{~F}$ J H Brims. 'University College London Hospitals NHS Foundation Trust, London, UK; ${ }^{2}$ University College London, London, UK

Introduction International guidelines for the management Primary spontaneous pneumothorax (PSP) vary on the definition of size, and treatment of PSP. The American consensus based ACCP guidelines recommend removal of air via an intercostal drain (ICD) in large PSP, and the BTS guidance suggest needle aspiration (NA) first, with quoted success rates of $30 \%-80 \%{ }^{1}$ In $2005 / 6$ there were 5954 finished consultant episodes for PSP in England. ${ }^{2}$

Methods We performed a retrospective audit of PSP presenting to the Emergency Department (ED) over a 24-month period. Electronic 